\title{
DEFICIÊNCIA VISUAL: POLÍTICA DE EDUCAÇÃO ESPECIAL EM AÇÃO PELO OLHAR DO PROFESSOR
}

\author{
VISUAL DISABILITY: SPECIAL EDUCATION POLICY \\ IN ACTION THROUGH THE TEACHER'S VIEW
}

\section{DISCAPACIDAD VISUAL: POLÍTICA DE EDUCACIÓN ESPECIAL EM ACCIÓN A TRAVÉS DE LA VISION DEL PROFESOR}

\author{
Merislandia Paulo da Silva Carvalho ${ }^{1}$ \\ Christiano Felix dos Anjos ${ }^{\text {II }}$ \\ IDoutoranda em Educação e bolsista Capes. \\ IIDoutorando em Educação. Professor e bolsista Capes.
}

\begin{abstract}
RESUmo Este estudo teve como objetivo conhecer e analisar como as políticas são colocadas em ação a partir da percepção dos professores de deficiência visual da rede de ensino do município de Vila Velha/ES. Como base teórica, contou com algumas contribuições de Boaventura de Sousa Santos para as discussões desencadeadas. Como aporte metodológico, apoiou-se em pressupostos da cartografia, que é um método que acompanha movimentos e investiga processos. O campo empírico foi composto com discussões em um grupo focal com os professores da área de deficiência visual da rede de ensino e, ao longo de nossas análises, consideramos as entrevistas e conversas com as pessoas que gestam a Educação Especial e a área de deficiência visual. Os resultados da pesquisa apontam uma expectativa entre a maioria dos professores especializados, considerando interessante ter um professor para acompanhar cada aluno com deficiência visual na sala de aula do ensino comum, desejo que advém da fragilidade da articulação entre professor especializado e professor da sala de aula. Aponta que a oferta de formação continuada para professores especializados vem acontecendo, porém faz-se necessário o avanço dessa oferta para outros profissionais da escola, visando à colaboração, item presente nos documentos locais.

Palavras-chave: Deficiência Visual; Educação especial; Escolarização; Inclusão ESCOLAR.
\end{abstract}


ABSTRaCr This study aimed to understand and analyze how policies are put into action from the perception of visually impaired teachers in the education network of the municipality of Vila Velha/ES. As a theoretical basis, he had some contributions from Boaventura de Sousa Santos for the discussions that started. As a methodological contribution, it was based on assumptions of cartography, which is a method that tracks movements and investigates processes. The empirical field was composed of discussions in a focus group with teachers from the visual impairment area of the education network and, throughout our analyzes, we considered the interviews and conversations with the people who manage Special Education and the visual impairment area. The results of the research indicate an expectation among the majority of specialized teachers, considering it interesting to have a teacher to accompany each student with visual impairment in the classroom of ordinary teaching, a desire that comes from the fragility of the articulation between specialized teacher and classroom teacher. It points out that the offer of continuing education for specialized teachers has been taking place, but it is necessary to advance this offer to other school professionals, aiming at collaboration, an item present in the local documents.

Keywords: Visual Impairment; Special Education; Schooling; School Inclusion.

RESUMEN Este estúdio tuvo como objetivo comprender y analizar cómo se ponen en práctica las políticas desde la percepción de los maestros con discapacidad visual en la red educativa del municipio de Vila Velha/ES. Como base teórica, tuvo algunas contribuciones de Boaventura de Sousa Santos para las discusiones que comenzaron. Como contribución metodológica, se basó em supuestos de cartografia, que es un método que rastrea movimientos e investiga procesos. El campo empírico se compuso de discusiones en un grupo focal con maestros del área de discapacidad visual de la red educativa y, a lo largo de nuestros análisis, consideramos las entrevistas y conversaciones con las personas que manejan la Educación Especial y el área de discapacidad visual. Los resultados de la investigación indican una expectativa entre la mayoría de los maestros especializados, considerando que es interesante tener un maestro que acompañe a cada estudiante con discapacidad visual en el aula de enseñanza ordinaria, un deseo que proviene de la fragilidad de la articulación entre el maestro especializado y el maestro de aula. Señala que se ha estado ofreciendo la oferta de educación continua para maestros especializados, pero es necesario avanzar esta oferta a otros profesionales de la escuela, con el objetivo de la colaboración, un elemento presente en los documentos locales.

Palabras Clave: Discapacidad Visual; Educación Especial; Escolaridad; Inclusión ESCOLAR.

\section{INTRODUÇÃo}

Neste texto, dedicamo-nos a discutir sobre os desdobramentos da política educacional de Educação Especial na visão dos professores especializados da área de deficiência visu$\mathrm{al}^{1}$ do município de Vila Velha. O estudo é um recorte de uma pesquisa maior intitulada

\footnotetext{
Neste estudo, o termo deficiência visual será usado para fazer referência tanto a alunos com baixa visão quanto a alunos cegos.
} 
"Deficiência Visual: da política educacional à organização escolar", financiada pela CNPq, defendida em 2016, no Programa de Pós-Graduação em Educação da Universidade Federal do Espírito Santo (PPGE/Ufes).

O objetivo deste texto é conhecer e analisar como as políticas são colocadas em ação a partir da percepção dos professores de deficiência visual da rede de ensino do município de Vila Velha/ES. São eles que vivem a realidade concreta da educação do aluno com deficiência visual no contexto escolar. Buscamos conhecer como as políticas chegam à escola na visão desses profissionais e entender como são colocadas em ação pelo conjunto de professores especializados que trabalham as questões da deficiência visual, dando visibilidade às políticas que se destacam e ganham relevância no contexto escolar.

Como aporte teórico, nos apoiamos em Boaventura de Sousa Santos. O autor nos ajuda a visibilizar aquilo que "pode" estar invisibilizado, criando espaços de inteligibilidade (SANTOS, 2007) entre os grupos e fazendo dialogar o conhecimento dos professores especializados entre si com o conhecimento da equipe gestora, visto que os professores falaram não só da política em ação, mas também das práticas organizativas da escola e do sistema. Discutiram ainda sobre as práticas pedagógicas, do fazer e do ensinar.

A partir das teorizações de Santos (2007), discorremos que a razão indolente, em suas diferentes formas, transforma interesses hegemônicos em "conhecimentos verdadeiros" e, dessa maneira, as realidades que não são legitimadas por essa razão são descartadas.

A sociologia das ausências visa a mostrar que o que não existe é produzido ativamente como não existente, ou seja, como "[...] uma alternativa não-credível ao que existe" (SANTOS, 2010, p. 102).

A tarefa dessa sociologia é ampliar o presente de forma a trazer ao debate os desafios da contemporaneidade que precisam ser resolvidos e tornar legítimas as experiências que são descartadas por não serem consideradas científicas.

Dessa forma, a função da sociologia das ausências é transformar as ausências em presenças. No caso do aluno com deficiência visual, é transformar o que em um primeiro momento a razão metonímica ${ }^{2}$ chamou de deficiência, em ações políticas, pedagógicas e curriculares que atentem verdadeiramente a esse sujeito.

Com a sociologia das emergências, Santos (2010, p. 116) postula contrairmos o futuro: "Contrair o futuro significa torná-lo escasso e, como tal, objecto de cuidado. O futuro não tem outro sentido nem outra direção senão os que resultam desse cuidado".

Para Santos (2010), a sociologia das emergências incide na substituição do vazio existente no futuro por um tempo cheio de possibilidades plurais e concretas e, ao mesmo tempo, utópicas e realistas; construção essa que se dá no presente por meio de cuidado.

$\mathrm{O}$ autor propõe a sociologia das ausências para expandir o presente, a sociologia das

\footnotetext{
2 A razão indolente tem duas formas, uma delas é a razão metonímica, que é obcecada pela ideia de totalidade sob a forma de ordem [...] e o todo tem absoluta primazia sobre cada uma das partes que o compõem. Por isso, há apenas uma lógica que governa tanto o comportamento do mundo como o de cada uma das suas partes [...]. As possíveis variações do movimento das partes não afectam o todo e são vistas como particularidades [...]. A simetria entre as partes é sempre uma relação horizontal que oculta uma relação vertical. Isso é assim porque, ao contrário do que é proclamado pela razão metonímica, o todo é menos e não mais do que o conjunto das partes. Na verdade, o todo é uma das partes transformada em termo de referência para as demais (SANTOS, 2010, p. 97-98).
} 
emergências para contrair o futuro e o trabalho de tradução para criar a inteligibilidade mútua entre as diversas experiências disponíveis sendo olhadas de forma horizontal e sem destruir sua identidade. Do ponto de vista da consciência cosmopolita e pensando na multiplicação e diversidade de experiências disponíveis, Santos (2010, p. 123-124) propõe o trabalho de tradução:

A tradução é o procedimento que permite criar inteligibilidade recíproca entre as experiências do mundo, tanto as disponíveis como as possíveis, reveladas pela sociologia das ausências e a sociologia das emergências [...]. As experiências do mundo são vistas em momentos diferentes do trabalho de tradução como totalidades ou partes e como realidades que se não esgotam nessas totalidades ou partes. Por exemplo, ver o subalterno tanto dentro como fora da relação de subalternidade.

Remetendo-nos ao aluno com deficiência visual, o trabalho de tradução procura captar os movimentos hegemônicos que impedem seu avanço e o que é possível para além dessa relação, buscando pelos inúmeros possíveis do cotidiano escolar, ou seja, procura tanto as experiências disponíveis quanto as experiências possíveis.

Para Santos (2010), o trabalho de tradução visa a criar inteligibilidade, coerência e articulação recíproca entre os diferentes movimentos de um mundo enriquecido pela multiplicidade e diversidade. Dessa forma, é necessário criar inteligibilidade entre o Núcleo de Educação Especial e a escola, e ainda, entre os profissionais envolvidos no contexto escolar no interior da própria escola. Vários profissionais desempenham suas atribuições pensando em um mesmo aluno. Com a ampliação da sociologia das ausências e da sociologia das emergências e com a coerência do trabalho de tradução, a possibilidade de um futuro melhor deixa de se assentar num futuro distante e busca a reinvenção do presente.

Com essas possibilidades em mente, cumpre sinalizar que a metodologia utilizada para conduzir nosso estudo sobre as políticas locais foi a cartografia, pois, com caráter processual de investigação, é um método que acompanha movimentos, investiga processos (PASSOS; KASTRUP; ESCÓSSIA, 2012). Apoiados na cartografia, entendemos que o fazer cotidiano dos professores emerge da política que se estabelece no local, consequência de vários saberes e práticas plurais de diferentes profissionais e escolas. A política não se dá no vácuo; ela se efetiva em um processo de construção nacional e local, “[...] uma vez que o processo político é entendido como multifacetado e dialético, necessitando articular as perspectivas macro e micro" (MAINARDES, 2006, p. 55). Enfatizamos o papel das macropolíticas sobre os profissionais que atuam no nível micro. "O método cartográfico se apresenta, assim, como alternativa importante para acompanhar o movimento [das] macro e micropolíticas [...]" (PASSOS; KASTRUP; ESCÓSSIA, 2012, p. 12).

Para tal, trabalhamos com grupo focal, e ao longo de nossas análises, consideramos as entrevistas e conversas com as pessoas que gestam a Educação Especial e a área de deficiência visual - profissionais do Núcleo de Educação Especial da rede de ensino de Vila Velha -, mostrando demandas, potências e fragilidades. Foram realizados dois grupos focais, no turno matutino ( $8 \mathrm{~h}$ às $11 \mathrm{~h}$ ) e turno vespertino ( $14 \mathrm{~h}$ às $17 \mathrm{~h})$, para atender às demandas dos professores que trabalham, de modo geral, em turnos e municípios diferentes. Dos 22 professores de deficiência visual que atuavam na rede de ensino de Vila Velha, 14 compareceram ao grupo focal - uma professora também faz parte da equipe de gestores do Núcleo de Educação Especial. Destes, sete no turno matutino e sete no turno vespertino. 
Com as discussões do grupo focal, vamos conhecer como os professores especializados da área de deficiência visual analisam e discutem a política na escola e como a política vai se constituindo, se fazendo, sendo vivida pelos professores nas suas ações cotidianas.

\section{A POLí́tica EM AÇão}

Neste item, dedicamo-nos a discutir sobre os desdobramentos da política educacional de Educação Especial na visão dos professores especializados da área de deficiência visual do município de Vila Velha.

Visando facilitar o entendimento nas discussões a seguir, discorremos sobre a função dos professores envolvidos na escolarização dos alunos indicados à Educação Especial e sua participação na escolarização desses alunos, buscando apontar algumas especificidades da área de deficiência visual.

Destacamos que os docentes são formados para sistematizar as ações realizadas com os alunos nas salas de aula do ensino comum e no atendimento educacional especializado, o que perpassa o trabalho colaborativo. Os professores da sala de aula do ensino comum têm formação para atuar com as disciplinas que ministram, e os professores especializados têm formação para apoiar as especificidades dos alunos público-alvo da Educação Especial, entre elas, a deficiência visual. Nesse contexto, ressaltamos que:

As frentes de trabalho de cada professor são distintas. Ao professor da sala de aula comum é atribuído o ensino das áreas do conhecimento, e ao professor [especializado] cabe complementar/suplementar a formação do aluno com conhecimentos e recursos específicos que eliminam as barreiras as quais impedem ou limitam sua participação com autonomia e independência nas turmas comuns do ensino regular (BRASIL/MEC, 2010, p. 19).

Ou seja, o professor da sala de aula tem a função de ministrar os conteúdos escolares, problematizando tais conteúdos com todos os alunos, inclusive com os alunos com deficiência visual. Dessa forma, o professor da sala de aula, como responsável pelo processo de ensino, deve implicar/mediar os significados dos sentidos que os conteúdos escolares trazem, dando condições reais para que os alunos com deficiência visual os interpretem.

O professor especializado tem a função de proporcionar recursos apropriados à aprendizagem, ou seja, é complementar, e não substitutiva. No caso do professor da área de deficiência visual, o professor tem a função de oportunizar a todos os alunos cegos ou com baixa visão a possibilidade de se desenvolver com a turma, fazendo as atividades como qualquer aluno e ao mesmo tempo em que os demais, visto que os "[...] processos de construção do conhecimento pela criança cega [e com baixa visão] são semelhantes aos das crianças videntes" (BRASIL, 2006, p. 26).

No município de Vila Velha o cargo de professor especialista se subdivide em duas categorias: professor do atendimento educacional especializado e professor do atendimento colaborativo. $^{3}$

3 Os documentos oficiais usam o termo "atendimento colaborativo" para se referir ao atendimento realizado pelos professores aos alunos de Educação Especial e para aludir aos professores de Educação Especial. São eles chamados de "professores do atendimento colaborativo". Neste texto, em alguns momentos, seguimos esse formato. 
O professor do atendimento educacional especializado, nas escolas da rede de ensino pesquisada, tem a função de atender ao aluno na sala de recursos multifuncionais no turno inverso ao da escolarização. ${ }^{4}$

Segunda a Política Nacional de Educação Especial na perspectiva da Educação Inclusiva (2008), o atendimento educacional especializado objetiva a identificação, elaboração e organização de recursos pedagógicos e de acessibilidade com vistas à autonomia e independência na escola e fora dela, por meio de programas de enriquecimento curricular, do ensino de linguagens e códigos específicos de comunicação e sinalização, de ajudas técnicas e tecnologia assistiva, diferenciando-se das atividades de sala de aula comum, com continuidade de estudos nos demais níveis de ensino e não substituindo a escolarização (ESPÍRITO SANTO, 2011, p. 16).

Já o professor do atendimento colaborativo, no município pesquisado, tem a função de acompanhar o aluno na sala de aula: "Na prática, o professor de deficiência visual trabalha junto com o professor do regular dentro da sala aula e faz todas as adaptações necessárias. Esse trabalho chama-se [atendimento] colaborativo" (Mário, ${ }^{5}$ profissional do Núcleo). Sobre tal atendimento, a equipe do Núcleo focaliza a Resolução $n^{\circ} .2$ - institui as Diretrizes Nacionais para a Educação Especial na Educação Básica - que, de acordo com Daiane, profissional do Núcleo, é uma legislação nacional que influencia muito a Educação Especial em Vila Velha. E completa: "Dá sustentação ao trabalho que se faz em sala de aula entre professores regentes e professores da Educação Especial. Sustenta o trabalho do especialista no turno de escolarização [...]".

Destacamos na Resolução $n^{\circ}$. 2, no artigo $8^{\circ}$., IV, sobre a organização das classes comuns, que as escolas devem prover "[...] serviços de apoio pedagógico especializado, realizado, nas classes comuns, mediante: a) atuação colaborativa de professor especializado em educação especial [...]" (BRASIL, 2001, p. 2). Na visão da equipe do Núcleo, o documento garante fundamentação sólida ao atendimento feito pelo professor ao aluno público-alvo da Educação Especial, fortalecendo a ideia de colaboração entre professores especializados e professores das salas de aula do ensino comum.

Feitas essas observações, iniciaremos a discussão sobre o que nos dizem os professores especializados da área de deficiência visual da rede de ensino do município de Vila Ve1ha. Assim, da equipe de professores especializados presentes no grupo focal, percebemos que o professor que faz o atendimento colaborativo ao maior número de alunos por turno tem o quantitativo de três alunos de séries diferentes em uma mesma escola. Em oito turnos de trabalho, os professores fazem o atendimento colaborativo a um único aluno, e em três turnos eles trabalham com dois alunos da mesma sala.

$4 \mathrm{Na}$ época do estudo, o aluno não era atendido no contraturno. Havia movimentos no Núcleo de Educação Especial para a efetivação da política de contraturno para a área de deficiência visual, o que já acontecia para o aluno com deficiência intelectual. Atualmente, conversando com uma professora da rede de ensino, ela esclarece que o município de Vila Velha oferece o atendimento realizado no contraturno de escolarização ao aluno com deficiência visual.

5 Todos os nomes utilizados no estudo são fictícios. 
Podemos perceber que há uma expectativa entre os professores. Consideram que é interessante ter um professor para acompanhar cada aluno.

\footnotetext{
Porque atender dois cegos sozinhos é impossível. Cego total precisa de ter um professor para cada aluno (José, professor especializado).

Dou conta entre aspas, porque meus dois alunos estão na mesma sala (Rosângela, professora especializada).

Trabalho em duas escolas em um turno. Não concordo em trabalhar em duas escolas, não dou conta (Elisa, professora especializada).
}

Essa expectativa advém da fragilidade da articulação entre professor especializado e professor da sala de aula do ensino comum. Entendemos que as possibilidades de acesso ao conhecimento devem ser com um movimento de responsabilização coletiva entre todos os profissionais da escola. Movimento esse essencial tanto para o desenvolvimento do trabalho dos professores da sala de aula quanto para o trabalho do professor especialista.

Sobre a expectativa dos professores, o Núcleo de Educação Especial esclarece:

Das questões da deficiência visual, a gente sabe a necessidade de ter um profes-
sor em cada escola, a cobrança, a exigência [...] é grande, é muito complicado.
[...] para o sistema não justifica você pagar o salário de um professor para aten-
der a um único aluno com deficiência visual. Tem casos que 'Ah é múltiplo, é
aquilo outro', nesse caso fica com um professor só para ele, mas tem situações
que tem que dividir a carga horária (Lídia, profissional do Núcleo).

A partir das teorizações de Santos (2007), discorremos que a razão indolente busca nos convencer de que, se não tivermos um professor para cada aluno, não teremos condições de acompanhar o educando, possibilitando o processo de aquisição do conhecimento. Ancorada nas proposições do autor, afirmamos que a sociologia das ausências e a sociologia das emergências nos permitem romper com essa ideia deixando nos movimentar, visando à processualidade e às articulações entre os envolvidos no cotidiano escolar do aluno.

Nesse contexto, embora os professores de deficiência visual presentes no grupo focal tenham a expectativa de ter um professor para acompanhar cada aluno, não ter o professor especializado na sala de aula em tempo integral, se, em articulação com a escola, potencializa outros movimentos, como podemos perceber na fala da professora Dalila: "Na minha ausência, os professores da sala de aula aplicam as atividades normalmente. As duas professoras da sala dão suporte, elas são muito boas". Ou ainda, "Os professores têm muito claro quem é a referência do aluno, e que nós estamos ali para apoiar. Os alunos também sabem que nós estamos ali para apoiar [...]" (Ana, professora especializada).

Há casos em que o professor da sala de aula do ensino comum prefere não ter o professor especialista participando de suas aulas, pois se sente responsabilizado pelo aluno, como observamos a seguir.

Fiz um acordo com a professora: não fico na sala com o aluno, porque ela é aquela professora alfabetizadora mesmo, gosta do que está fazendo e se dedica, então fico fora da sala de aula os dois dias que vou lá, adaptando atividade, am- 
pliando e tal, para que ele possa ter atividade ampliada os cinco dias. Se eu ficar na sala com ele, não consigo fazer o material (Elisa, professora especializada).

Essa linha de ação coaduna com as proposições do Núcleo de Educação Especial. A profissional do Núcleo, Lídia, argumenta que, “[...] quando se fala de um trabalho colaborativo, não podemos perder de vista essa ideia de adaptar o material para que o aluno tenha tudo que está sendo dado na sala de aula, porque esse aluno já tem um professor na escola".

E, ainda, "É tentar fazer um trabalho de articulação" (Daiane, profissional do Núcleo). Mas, infelizmente, "Em algumas escolas não funciona, porque o professor deixa tudo por conta do professor especializado, temos que trabalhar isso" (Lídia, profissional do Núcleo).

Uma questão discutida no grupo focal diz respeito a quem são os alunos e como se organizam as práticas educacionais na escola. Sobre seus alunos, o grupo tinha suas inquietações. Dos 22 alunos atendidos pelos professores presentes no grupo focal, especificamente em relação à deficiência visual, quatro alunos são cegos e os demais têm baixa visão. Do total de alunos atendidos pelos professores presentes, sete acompanham o currículo da turma com as dificuldades comuns de qualquer aluno na escola. Um deles, o único da educação infantil do grupo de professores ali presentes, tem microcefalia, o que ocasionou uma deficiência intelectual.

Onze desses alunos têm muita dificuldade em acompanhar o currículo, mas com a ajuda do professor do atendimento colaborativo, quando este está presente na sala de aula, é possível, como nos relata a professora Dalila: "Mesmo eles apresentando muitas dificuldades, quando estou na sala, eles acompanham o currículo, mais pra mais do que pra menos, porque buscamos dar a eles condições pra isso".

Desses onze alunos que acompanham a turma com dificuldade, quatro são indicados pelos professores como alunos com alguma deficiência: um é apontado pela professora com características de autismo, dois com deficiência intelectual (um devido à microcefalia) e um é surdo. Para além, um aluno com transtorno de déficit de atenção/hiperatividade.

Do total de alunos, três são crianças com deficiência múltipla bem severa, dois deles extremamente comprometidas na fala, no andar, na coordenação motora, na cognição, entre outros. O outro aluno com deficiência múltipla é bastante comprometido, no entanto, menos que os colegas, "[...] consegue andar e tem boa coordenação motora, precisa ser incentivado e ainda não consegue lidar bem com o material escolar, está em processo, estamos trabalhando para que ele chegue lá" (Elza, professora especializada).

Recorremos a Santos (2007) para evidenciar a fala da professora. Ela disse "[...] ainda não [...]". Enfatizamos o "ainda não", o que vemos como muito positivo, pois dá a ideia de que busca a processualidade da relação desse aluno com a sala de aula.

Nesse contexto, com esse grupo de alunos é trabalhada a estimulação, com o intuito de prepará-los para a alfabetização, como pegar no lápis, pintar, jogar e pegar objetos. De todos os alunos, um não frequentava a sala de aula, porque, de acordo com a professora, o comprometimento dele não permite essa ação, e os outros dois alunos frequentam por um período. Quando ficam extremamente inquietos, o professor é obrigado a tirá-los da sala. 
Seis alunos não acompanham a turma. Estão bem defasados em relação à idade/ano de matrícula. A professora Mercedes enfatiza:

O aluno está no $4^{\circ}$ ano, em processo de alfabetização. Reconhece as sílabas e está na fase de formar pequenas palavras. Tem síndrome de Lowe que afeta a visão, os rins e o cognitivo. Tem dificuldade na coordenação motora, ou melhor, não foi estimulado.

Nessa linha de raciocínio, os “[...] adultos que acompanham a criança com deficiência visual têm a função de ajudá-la a utilizar as mãos para descobrir o mundo e se interessar por ele. Esse trabalho recebe o nome de estimulação precoce" (BRASIL, 2000, p. 25).

De modo geral, os professores relataram que os alunos com deficiência visual têm algum comprometimento para além do visual. No entanto, chegaram a um consenso interessante:

Eu tenho quadro alunos, nenhum deles é só visual. Um deles nasceu cego e, quando nasce cego, e não é estimulado o tempo todo, acaba tendo um retardo intelectual [...]. Às vezes meu aluno entra em órbita, começa a se bater, gritar e só depois que passa isso, ele volta para o conteúdo (Isadora, professora especializada).

Nessa questão, apoiamo-nos em Vygotsky (apud VEER; VALSINER, 2006), na afirmativa de que um "defeito físico" não afeta a personalidade do indivíduo de forma direta. $\mathrm{O}$ autor afirma que todas as deficiências corporais:

[...] afetavam antes de tudo as relações sociais das crianças e não suas interações diretas com o ambiente físico. O defeito orgânico manifestava-se inevitavelmente como uma mudança na situação social da criança. Assim, pais, parentes e colegas irão tratar a criança deficiente de uma maneira muito diferente das outras crianças, de um modo positivo ou negativo (VEER; VALSINER, 2006, p. 75).

Para que a criança se desenvolva, deve ser despertada sua "[...] curiosidade e o interesse pela descoberta do mundo, estimulando a iniciativa e a autonomia da criança com deficiência visual" (BRASIL, 2010, p. 26). Caso a criança não seja estimulada, pode parecer uma criança com deficiência intelectual, como nos relata a professora: "O que aconteceu com o aluno foi isso: falta de estimulação. Tem 12 anos e parece ter 5, parece ter deficiência intelectual" (Isadora, professora especializada).

Os professores analisam a organização política disponibilizada para o aluno com deficiência visual no município de Vila Velha. De acordo com os educadores presentes no grupo focal, "A política atual é acompanhar o aluno com deficiência visual no turno em que estiver matriculado" (Elisa, professora especializada).

Quando os professores foram perguntados sobre os apoios na escola para os alunos com deficiência visual, ouvimos respostas de diferentes perspectivas. Na opinião de alguns deles, em algumas escolas existem apoios físicos e computacional.

A nossa sala é bem completa, apesar de ser material antigo, de 2008, tem que ir fazendo uma reposição. Muitos jogos adaptados em alto-relevo, textura, tudo que tem dentro da sala de recursos para deficiente visual - puff, tapete, as má- 
quinas Braille, folha com gramatura adequada para o Braille, impressora Braille, computador, notebook, lupa eletrônica, reglete, sorobã. E usamos bastante, trabalhamos muito com aqueles materiais. Temos um material muito interessante (Elza, professora especializada).

O DosVox, os softwares, eles dominam o uso desses programas de voz, usamos o Braille Fácil para imprimir (Carla, professora especializada).

Nas falas das professoras, podemos observar a existência e incorporação de tecnologia assistiva em seu cotidiano, mesmo que, em alguns casos, o material de suporte seja antigo. De acordo com a discussão citada, os fazeres diários desses professores englobam "[...] serviços que objetivam promover a funcionalidade, relacionada à atividade e participação [...]" (BRASIL, 2007, apud MANZINI, 2011, p. 46) do aluno com deficiência visual, buscando colocá-lo em condições de aprendizagem na sala de aula do ensino comum.

Em relação às tecnologias de informação e comunicação, concordamos com Martins (2010), que defende a ideia de que, para alguns alunos, podem não ser apenas benéficas, mas imprescindíveis para a equiparação das oportunidades para garantir o acesso ao currículo.

Existem alguns professores que dizem precisar de maior apoio, inclusive do Núcleo e da escola: "Lápis 6 B para o aluno? Na minha escola nem ele compra, nem a prefeitura, nem a escola, somos nós" (Rosângela, professora especializada). Dependendo do material, os professores sabem que, se houver insistência, conseguem algum apoio: "O único material que eu tenho é um plano inclinado, porque eu liguei para o Núcleo e perturbei, perturbei, perturbei... até me arrumarem um plano inclinado" (Elisa, professora especializada).

Em relação ao apoio existente na escola, o Núcleo argumenta que, em alguns casos, sabem da necessidade da "[...] Secretaria de Educação fazer um documento para transferir o material de escolas que não precisam no momento para as que precisam" (Lídia, profissional do Núcleo). A profissional Lídia ainda lembra: "Tem também a responsabilidade do diretor na aquisição de alguns materiais para o dia a dia".

Nessa linha de raciocínio, dois professores dialogam com o apoio humano, fundamental para que o direito social de educação aconteça. A título de exemplo, trouxemos a professora Mercedes: "Na escola, temos total apoio da direção, pedagoga e coordenação, o que faz com que eu consiga fazer um trabalho muito bom". Dialogando com Santos (2007, p. 39), "Isso vai criar outra maneira de entender, outra maneira de articular conhecimentos, práticas, ações coletivas, de articular sujeitos coletivos".

Uma grande tensão no município de Vila Velha, de acordo com os professores especializados, diz respeito à sala de recursos multifuncionais. Os profissionais da rede de ensino de Vila Velha, sejam eles do Núcleo, sejam das escolas, chamam a sala que realiza o atendimento no contraturno de escolarização do aluno de sala de atendimento educacional especializado. ${ }^{6}$

6 Cabe aqui ressaltar nosso entendimento sobre atendimento educacional especializado. Concordamos com Baptista (2013, p. 58), que atendimento educacional especializado deve ser “[...] uma ação plural em suas potencialidades e metas, sistêmica ao mirar (e modificar) o conjunto de relações que contribuem para a estagnação do sujeito e sua provável dificuldade de aprendizagem e desenvolvimento". Em suas análises, o autor considera atendimento educacional especializado como sinônimo de ação pedagógica. Nesse contexto, atendimento educacional especializado é entendido por nós como organizador de apoios e recursos a tudo que demanda a sala de aula do ensino comum. 
No município existem escolas que têm as duas salas: "Sala de recurso, usada pelo professor no turno do aluno; sala de atendimento educacional especializado, usada no contraturno da escolarização do aluno. Tem escola que só tem uma. Na minha escola não tem nenhuma" (Raquel, professora especializada).

Sala de atendimento educacional especializado é aquela do contraturno de escolarização do aluno, disponibilizada pelo MEC, equipada para atender às especificidades dos alunos público-alvo da Educação Especial. "Sala de $\mathrm{AEE}^{7}$ é aquela que chega o material novinho do MEC, e sala de recurso, onde meu aluno com deficiência visual entra. Nessa, o material que nós temos é antigo" (Elza, professora especializada).

Mas há controvérsias entre os professores da Rede. "Na minha escola é diferente. [...]. $\mathrm{Na}$ minha sala os meninos [com deficiência intelectual] vêm no contraturno, mas o professor do colaborativo também leva o menino, faz um jogo, volta. Gente! O espaço físico é da escola [...]" (Lia, professora especializada). Ou ainda: "Eu fico na mesma sala que a professora do atendimento educacional especializado do contraturno. Ela tem o material dela, eu tenho o meu" (Isadora, professora especializada).

As análises desses dados apontados pelos professores especializados da área de deficiência visual indicam que a proposta da sala de recursos multifuncionais se diferencia nas diversas escolas da rede de ensino.

Nas entrelinhas dos relatos dos professores, foi possível entender que essa diferenciação entre as salas causa desconforto para a maioria dos professores do atendimento colaborativo, visto em algumas escolas eles serem impedidos de usufruir de materiais pedagógicos específicos que chegam do Ministério da Educação. Ou ainda:

\footnotetext{
Ninguém pode entrar na sala do contraturno, é uma orientação do Núcleo de Educação Especial, não pode e pronto (Carla, professora)!

Pera aí, eu não digo que vou descer da sala com algum aluno, eu digo que preciso entrar lá e ficar de boca calada simplesmente digitando e ampliando. Ela diz: 'Não! Não pode! Orientação do Núcleo' (Elisa, professora)!
}

Sobre as diferentes formas em lidar com as controvérsias da sala de recursos multifuncionais, recorremos a Mainardes (2006, p. 53) que explica que, com base em Ball e Bowe, no contexto da prática, "[...] a política está sujeita a interpretação e recriação [...]", lugar que produz implicações e consequências que podem refletir em transformações significativas na política original, haja vista que as políticas não são simplesmente "implementadas" dentro desse contexto da prática; elas estão sujeitas à compreensão, podendo ser reelaboradas.

Corroborando com os relatos anteriores sobre as orientações do Núcleo de Educação Especial, as controvérsias e ambiguidades a respeito das salas de atendimento feito no contraturno da escolarização do aluno público-alvo da Educação Especial têm outros entraves. Destacamos a seguir trechos em que os professores especializados da área de deficiência visual parecem não acreditar nas confusões causadas por essa diferenciação entre as salas.

Teve um ano que algumas pessoas do Núcleo de Educação Especial foram na escola que eu trabalho e levaram o material que estava na sala de recursos para

Atendimento educacional especializado. 
a sala do AEE. Era tudo coisa para aluno cego: globo em Braille, um monte de coisas em alto-relevo, material pedagógico que veio para aluno cego do MEC. Mas, segundo o Núcleo, eles tinham que levar pra sala de AEE pra guardar, para não estragar, porque, se ficasse lá, ia estragar tudo. Nem acreditei quando isso aconteceu (Elza, professora especializada).

Ouvi a professora do AEE lá da sua escola dizer que é orientação do Núcleo mesmo (Maria, professora especializada).

Só recebemos a impressora Braille depois de dois anos que estava na caixa, guardada, pra não estragar, no armário. Ficamos dois anos digitando na máquina Braille. E a impressora Braille estava fechadinha, enferrujando, e ninguém podia tocar. [...] (Carla, professora especializada)!

Sobre o acesso à sala e aos materiais, o Núcleo tem a seguinte posição: "A sala de atendimento educacional especializado é a sala de recursos multifuncional, onde todos os professores especializados têm acesso, inclusive os professores de deficiência visual" (Lídia, profissional do Núcleo).

Posteriormente, depois do grupo focal, após falarmos um pouco sobre tal discussão ocorrida, outra profissional argumenta: "Não entendo porque isso está acontecendo. Já tivemos um problema similar e pensei que isso já estava resolvido há tempos" (Daiane, profissional do Núcleo). ${ }^{8}$

Nessa produção de dados da pesquisa, buscamos informações a respeito da política de Educação Especial em documentos do Núcleo, atuais e antigos, também em estudos sobre o município.

O fato é que há um documento de 2012 que estabelece que é vedada a utilização do espaço reservado para o contraturno de matrícula para outros fins (Vila Velha, 2012). Sobre esse assunto, Melo (2016) destaca que foi uma maneira de proteger os materiais e equipamentos existentes nessas salas. O que muitas das escolas e dos professores do contraturno faziam era cumprir tais determinações do Núcleo. Melo (2016) argumenta que tal determinação surgiu para proteger o material, e não para proibir o uso deles por quem faz jus à proposta do Ministério da Educação.

No entanto, entendemos ser contraditória tal visão do Núcleo de Educação Especial quando fez tal ressalva, que inibe a utilização de material específico para alunos com deficiência visual por professores que atendem ao aluno no turno de escolarização. Principalmente porque, como gestores da Educação Especial, o Núcleo sempre teve clareza de que em algumas escolas existem diferentes salas usadas pelos professores em suas especificidades de horários.

De acordo com Mainardes (2006, p. 53), “[...] os professores e demais profissionais exercem um papel ativo no processo de interpretação e reinterpretação das políticas educacionais [...]". Assim, o que eles pensam e no que acreditam têm implicações no processo de implementação das políticas. O que coaduna fortemente com as interpretações individuais sobre o tema nas escolas da Rede.

8 A partir da presença de uma professora no grupo focal, que também trabalhava no Núcleo de Educação Especial, cabe pontuar que, no decorrer do estudo, os profissionais que gestam a Educação Especial foram à escola que a controvérsia se apresentou com maior intensidade buscando resolver a questão: o material que ficava "guardado" foi disponibilizado para o professor de deficiência visual. Os profissionais disseram que essa ação se estenderia às demais escolas, de acordo com a demanda. 
Com essas controvérsias que acontecem/aconteceram no município de Vila Velha, os professores especializados da área de deficiência visual, em sua maioria, têm mais dificuldades e morosidade em realizar seu trabalho pelo impedimento de usar diversos materiais específicos ou até mesmo o computador. Dessa forma, os alunos podem ficar prejudicados pela falta de comunicação entre sistema e escola, ou pela comunicação contrária ao objetivo da sala de recursos multifuncionais.

Sobre os processos de organização para o aluno, os professores do atendimento colaborativo atendem ao aluno no turno de escolarização: "Sento do lado dele e fico na sala de aula o tempo inteiro" (Lúcia, professora especializada). E outra professora complementa: "O que eu faço: sento com o professor regente, pego o conteúdo daquele trimestre e vou adaptar as atividades de acordo com o currículo. O aluno acompanha as adaptações que eu tenho como proposta" (Mercedes, professora especializada).

Algumas escolas da Rede são frágeis nesse sentido. Uma professora reclama: “A gente na escola não consegue pegar o material com antecedência com o professor, tem que fazer na hora" (Lia, professora especializada).

As coisas não estão resolvidas para o aluno com deficiência visual, no entanto vemos muitos movimentos. Muitas escolas caminham no sentido de articulação entre todos os profissionais da escola, em outras esse processo é frágil. É urgente a ação vislumbrada pelo Núcleo de formação para todos os profissionais da escola objetivando dialogar sobre a necessidade de articulação e a responsabilização coletiva entre todos.

De acordo com a versão preliminar - documento em vigor - do Projeto de Atuação do Núcleo de Educação Especial/Semed (VILA VELHA, 2013), um dos princípios orientadores da política do Núcleo se assenta na oferta de formação continuada para os professores do ensino regular e da Educação Especial, pedagogos e diretores das unidades de ensino (VILA VELHA, 2013). O enfoque nessa premissa evidencia a tentativa do município em avançar na área de Educação Especial.

A proposta de formação do Núcleo envolvendo toda a escola, de acordo com os professores especializados, ainda não se efetivou. Sobre a formação com professores especializados e professores da sala de aula de ensino comum, a professora Rosângela argumenta:

Falavam que iam fazer formação da Educação Especial com o professor regente. E tem alguns professores regentes que cobram, [...] eles precisam de formação. Temos muitos problemas com o professor porque passam uma coisa pra gente na nossa formação, e na formação lá, do professor regular, isso não chega.

Embora haja fragilidades de formação, queremos visibilizar que uma das questões que o Núcleo se coloca como responsável é a organização de formação continuada para os professores de Educação Especial: “Tem a formação geral e a formação com os encontros por área, no nosso caso, deficiência visual” (Mário, profissional do Núcleo). No caso dos professores de deficiência visual, tem um projeto de formação continuada em que reunimos "[...] os professores uma vez por mês, trazendo alguém de fora para fazer uma fala, ou a gente mesmo [...]" (Daiane, profissional do Núcleo).

As dinâmicas formativas motivam os atores do processo ensino-aprendizagem a olhar o currículo pensando nas diferenças humanas, o que é essencial nas ações que pretendem oportunizar o direito à educação para todos os alunos. 
E mais, de acordo com a Nota Técnica SEESP/GAB nº 11 (BRASIL, 2010), compete às escolas estabelecer redes de apoio e colaboração com as outras escolas da rede de ensino, promovendo formação dos professores, acesso aos serviços e recursos de acessibilidade, produção de materiais didáticos acessíveis e desenvolvimento de estratégias pedagógicas.

Sabemos que é complexa a realidade, mas as soluções estão aí, o que leva a nos apoiar em Santos (2007, p. 24), porque “[...] na realidade há muitas alternativas". Sabemos o que precisa ser feito, então precisamos criar inteligibilidade entre os grupos, entre as escolas, entre os professores de deficiência visual e os professores da sala de aula do ensino comum, produzindo sentidos. "É traduzir saberes, traduzir práticas e sujeitos de uns aos outros, é buscar inteligibilidade sem 'canibalização', sem homogeneização [...]” (SANTOS, 2007, p. 38).

É a busca pela articulação de experiência entre todos os profissionais da educação, visando ao acesso ao conhecimento para o aluno com deficiência visual.

Considerando os depoimentos dos professores especializados, é urgente que a proposta de formação pensada pelo Núcleo de Educação Especial se efetive também com os professores da sala de aula regular, pois eles, na maioria, parecem conseguir realizar um trabalho interessante com os alunos com deficiência visual, no entanto, percebemos que seria um trabalho mais rico, se tivesse participação mais efetiva de todos os profissionais da escola, principalmente dos professores da sala de aula do ensino comum.

Enfim, "[...] vamos criar a inteligibilidade recíproca no interior da pluralidade" (SANTOS, 2007, p. 39). É possível traduzir o trabalho dos professores especializados e dos professores da sala de aula do ensino comum em função da qualidade dos trabalhos desenvolvidos com todos os alunos da turma, inclusive alunos com deficiência visual, já que "[...] sobre a base de uma experiência rica não desperdiçada podemos realmente pensar em uma sociedade mais justa" (SANTOS, 2007, p. 41).

\section{CONSIDERAÇões FINAIS}

O presente texto teve como objetivo conhecer e analisar como as políticas são colocadas em ação a partir da percepção dos professores de deficiência visual do município de Vila Velha/ES.

A metodologia cartográfica nos permitiu buscar um olhar atento, determinante na produção de dados da pesquisa e sensível à realidade, objetivando entender como se colocavam as questões cotidianas, não apontando como certo ou errado, mas com um olhar que buscasse acompanhar a processualidade. Seguindo essa linha de pensamento, destacamos que o método cartográfico é acompanhar processos, e não representar objetos (POZZANA de BARROS; KASTRUP, 2012), entendendo aqui processo segundo a ideia de processualidade.

No movimento de análise dos dados do grupo focal com professores da área de deficiência visual, discutimos os desdobramentos da política vivida nas escolas da rede de ensino do município, observando como são colocadas em ação pelo conjunto de professores especializados da área de deficiência visual. Com esse movimento, mostramos demandas, potências e fragilidades.

Percebemos que existe uma expectativa quanto à ação dos professores da área, pois consideram importante ter um professor para acompanhar o aluno de forma individualizada 
nas escolas da rede de ensino. Em nossas análises, a expectativa de ter um professor por aluno advém da fragilidade da articulação entre professor especializado e professor da sala de aula do ensino comum.

$\mathrm{Na}$ contramão dessa expectativa, as narrativas do grupo focal também nos evidenciaram que não ter o professor especializado na sala de aula em tempo integral, se em articulação com a escola - que significa ter o apoio do pedagogo, diretor e demais profissionais visando ações inclusivas e incentivando a responsabilização coletiva -, fomenta outros possíveis, como a responsabilidade do professor da sala de aula do ensino comum com o aluno com deficiência visual.

Destacamos que, quando o professor da sala de aula tem o professor do atendimento colaborativo para dar suporte às especificidades do aluno, aquele não deve se eximir de sua responsabilidade de ensinar. Acreditamos que todos os profissionais da escola (diretores, pedagogos, professores da sala de aula do ensino comum e professores especializados) devem instituir situações que possam criar "inteligibilidade" na sala de aula entre/com os professores, trabalhando em colaboração, visando à escolarização - e não em dependência -, buscando diálogo com a especificidade do aluno com deficiência visual. Essa é uma ação que se faz necessária para suprir o direito que tem o aluno de acesso ao conhecimento.

Santos (2007) aposta que a possibilidade de um futuro melhor não está distante, se reinventarmos o presente, ampliado pela sociologia das ausências e das emergências, tornando tal futuro coerente, a partir do trabalho de tradução, criando constelações de saberes e práticas para fornecer alternativas credíveis, propiciando inteligibilidade recíproca no interior da diversidade, entre as experiências, tanto as disponíveis, quanto as possíveis.

Esse entrosamento vai originar outras maneiras de entender o aluno, outras formas de articulação de conhecimentos, de práticas e de ações coletivas (SANTOS, 2007), pois, a partir da sala de aula do ensino comum, com articulação entre os profissionais da escola, é que se fazem movimentos que oportunizam ao aluno com deficiência visual as mesmas oportunidades dadas aos outros alunos da sala de aula para o acesso ao conhecimento.

\section{REFERÊNCIAS}

BAPTISTA, Claudio Roberto. Ação pedagógica e a educação especial: para além do AEE. In: JESUS, Denise Meyrelles de; BAPTISTA, Claudio Roberto; CAIADO, Katia Regina Moreno (Org.). Práticas pedagógicas na educação especial: multiplicidade do atendimento educacional especializado. Araraquara, SP: Junqueira \& Marin, 2013, p. 43-62

BRASIL. Deficiência visual, 2000. Cadernos da TV Escola. Brasília: MEC: Secretaria de Educação a Distância, 2000. Disponível em: $<$ http://www.dominio publico.gov.br/download/texto/me000344.pdf>. Acesso em: 27 jun. 2016.

BRASIL. Conselho Nacional de Educação. Câmara de Educação Básica. Resolução CNE/ CEB $n^{\circ}$. 2, de 11 de setembro de 2001. Institui Diretrizes Nacionais para a Educação Especial na Educação Básica. Diário Oficial da União, Brasília, 14 set. 2001. Seção 1E, p. $39-40$. 
BRASIL. Sala de recursos multifuncionais: espaço para atendimento educacional especializado. Brasília: MEC/Seesp, 2006.

BRASIL. Nota Técnica - $\mathbf{n}^{\mathbf{0}}$. 11/2010, de 7 de maio de 2010. MEC: Seesp. Disponível em: http://portal.mec.gov.br/index.php?option=comdocman\&view = down load\&alias=5294-notatecnica-n112010\&category. Acesso em: 29 jun. 2016.

BRASIL. A educação especial na perspectiva da inclusão escolar: a escola comum inclusiva. Fortaleza: MEC/Seesp, 2010.

ESPÍRITO SANTO (Estado). Secretaria de Estado da Educação. Diretrizes da Educação Especial na Educação Básica e Profissional para a Rede Estadual de Ensino do Espírito Santo. Educação Especial: inclusão e respeito à diferença, 2. ed., 2011.

MAINARDES, Jefferson. Abordagem do ciclo de políticas: uma contribuição para a análise de políticas educacionais. Educ. Soc., Campinas, v. 27, n. 94, p. 47-69, jan./abr. 2006.

MANZINI, Eduardo José. Formação de professores e tecnologia Assistiva. In: CAIADO, Katia Regina Moreno et al. Professores e educação especial: formação em foco. Porto Alegre: Mediação, 2011, p. 45-63.

MARTINS, Mary Grace. Direito à educação e acessibilidade às tecnologias de informação e comunicação por alunos com deficiência, 2010. Dissertação (Mestrado em Educação) - Programa de Pós-Graduação da Faculdade de Educação da Universidade de São Paulo. São Paulo: s.n., 2010.

MELO, Douglas Christian Ferrari de. Entre a luta e o direito: políticas públicas de inclusão escolar de pessoas com deficiência visual, 2016. Tese (Doutorado em Educação) - Universidade Federal do Espírito Santo, Vitória, 2016.

PASSOS, Eduardo; BENEVIDES de BARROS, Regina. A cartografia como método de pesquisa-intervenção. In: PASSOS, Eduardo; KASTRUP, Virgínia; ESCÓSSIA, Liliana da (Org.). Pistas do método cartográfico: pesquisa-intervenção e produção de subjetividade. Porto Alegre: Sulina, 2012, p. 17-31.

PASSOS, Eduardo; KASTRUP, Virgínia; e ESCÓSSIA, Liliana. Pistas do método cartográfico: pesquisa-intervenção e produção de subjetividade. Porto Alegre: Sulina, 2012.

POZZANA de BARROS, Laura; KASTRUP, Virgínia. Cartografar é acompanhar processos. In: PASSOS, Eduardo; KASTRUP, Virgínia; ESCÓSSIA, Liliana da (Org.). Pistas do método cartográfico: pesquisa-intervenção e produção de subjetividade. Porto Alegre: Sulina, 2012, p. 52-75. 
SANTOS, Boaventura de Sousa. Renovar a teoria crítica e reinventar a emancipação social. Tradução de Mouzar Benedito. São Paulo: Boitempo, 2007.

SANTOS, Boaventura de Sousa. A gramática do tempo: para uma nova cultura política, 3. ed. São Paulo: Cortez, 2010 (Coleção Para um Novo Censo Comum, v. 4).

VEER; René Van Der; VALSIVER; Jaan. Vygotsky: uma síntese. Tradução de Cecília C. Bartalotti. São Paulo: Edições Loyola, 5. ed., 2006.

VILA VELHA. Secretaria Municipal de Educação, Cultura e Esportes. Educação Especial: orientações pedagógicas. Vila Velha, 2012.

VILA VELHA. Secretaria Municipal de Educação, Cultura e Esportes. Projeto de Atuação do Núcleo de Educação Especial/Semed (versão preliminar). Vila Velha, 2013.

DADOS DOS AUTORES:

Merislandia Paulo da Silva Carvalho

Doutoranda em Educação e bolsista Capes.

\section{Christiano Felix dos Anjos}

Doutorando em Educação. Professor e bolsista Capes.

Submetido em: 27-8-2019

Aceito em: 24-1-2020 